\title{
CULTURA ORGANIZACIONAL EM HOSPITAIS PRIVADOS DE NATAL/RN
}

\author{
ORGANIZATIONAL CULTURE IN PRIVATE HOSPITAIS NATAL/RN
}

\author{
Lidiane de Medeiros Lucena \\ Universidade Federal do Rio Grande do Norte - UFRN \\ José Arimatés de Oliveira \\ Universidade Federal do Rio Grande do Norte - UFRN
}

\section{RESUMO}

O presente trabalho teve como objetivo caracterizar a cultura organizacional dos hospitais, enfatizando as práticas e os valores organizacionais. A metodologia utilizada na pesquisa foi de caráter descritivo e explicativo. A pesquisa ocorreu através da aplicação do Instrumento Brasileiro para a Avaliação da Cultura Organizacional - IBACO, com 283 sujeitos distribuídos em três hospitais da rede privada de Natal/RN. As evidências encontradas pelo estudo foram analisadas através do software estatístico SPSS, com a técnica multivariada de análise fatorial. A partir dessa análise, foram obtidos cinco fatores distribuídos entre práticas e valores organizacionais, que foram: as práticas de recompensa e treinamento; integração externa e promoção do relacionamento interpessoal; e, os valores de satisfação, bem-estar e cooperação dos empregados e profissionalismo competitivo. De forma geral, a prática que mais se destacou foi a de recompensa e treinamento, enquanto o valor de destaque foi o de satisfação, bem-estar e cooperação dos empregados.

Palavras-chave: Cultura organizacional. Cultura hospitalar. Práticas e valores organizacionais.

\begin{abstract}
The present work aimed to characterize the organizational culture of hospitals, emphasizing organizational practices and values. Methodology used in this research had a descriptive and explaining character. The research occurred through application of the Brazilian Instrument for the Evaluation of Organizational Culture - IBACO, with 283 subjects distributed at threeprivate hospitals in Natal/RN. Evidences found by the study were analyzed though the statistic software SPSS, with multivariate technique of factorial analysis. From this analyze, five factors distributed between practices and values, which were: practices of reward and training; external integration and promotion of interpersonal relationship; and values of satisfaction, welfare and cooperation of employees and competitive professionalism. In general, the practice that stood out was reward and training, while the value of note was satisfaction, welfare and cooperation of employees.
\end{abstract}

Keywords: Organizational culture. Hospital culture. Organizational practices and values. 


\section{INTRODUÇÃO}

A cultura da empresa serve para seus membros como uma referência, de maneira tal que os padrões e as regras estejam esclarecidos de forma que os indivíduos compreendam como devem se conduzir na organização. A difusão ampla e intensa da cultura organizacional pelos colaboradores faz com que eles possam agir em prol dos objetivos organizacionais. A cultura organizacional é um elemento que intenciona a solução de dois problemas: a manutenção da integração interna, para garantir a habilidade de adaptação e o funcionamento diário da organização; e a adaptação ao meio ambiente em que está inserida, sobrevivendo e crescendo com o surgimento das adversidades (SCHEIN, 1992). Assim, quando existe consenso entre os dois, a organização tem uma maior probabilidade de atingir seus objetivos.

Conhecer a cultura de uma organização é importante para que ela passe a ser utilizada como uma estratégia de melhoria para a organização. Dias (2003) afirma que o estudo da cultura organizacional dá subsídios para a compreensão de interesses de grupos determinados, das relações de poder presente nas organizações, nos comportamentos contraditórios dos membros, como também nas regras estabelecidas que não sejam regulamentadas. Portanto, ao ser identificado os valores e as práticas que regem a organização torna-se mais fácil detectar o impacto que a cultura pode ter no funcionamento da empresa. Um hospital é uma organização que apresenta uma grande complexidade na sua infraestrutura, nos seus processos, nos seus recursos e também na sua cultura. Trata-se de uma organização com uma diversidade de serviços, setores e profissionais tendo o intuito de melhorar a excelência e a qualidade dos serviços prestados aos usuários. Portanto, caracterizar sua cultura organizacional, através das suas práticas e valores auxilia aos seus membros terem de forma clara os objetivos a que devem alcançar.

Diante disto, caracterizar a cultura organizacional na organização hospitalar trata-se do problema central desse estudo. Para tanto, ele tem como objetivo caracterizar a cultura organizacional em três hospitais da rede privada de Natal/RN, identificando as práticas e os valores utilizados pelos hospitais.

A presente pesquisa serve de subsídio para compreender melhor o setor da saúde, em especial a organização hospitalar. Além disso, o estudo da cultura organizacional em três hospitais aumenta a proporcionalidade dos valores e práticas utilizados em hospitais.

\section{CULTURA ORGANIZACIONAL}

A cultura organizacional apresenta várias definições, sendo apresentadas em diferentes contextos. A diversidade de explicações a respeito desta cultura no Brasil é relativamente recente, datada no início da década de 80 . No entanto, é consenso entre os estudiosos que a cultura existe nas organizações e é um importante instrumento para auxiliar e predeterminar o comportamento nas organizações, bem como funcionar como mecanismo de controle.

De vários conceitos abordados, um dos conceitos clássicos dado à cultura organizacional foi trazido por Schein (1992, p.12) na qual especifica: A cultura organizacional é um modelo de pressupostos básicos, que determinado grupo tem inventado, descoberto ou desenvolvido no processo de aprendizagem para lidar com problemas de adaptação externa e integração interna. Uma vez que os pressupostos tenham funcionado bem o suficiente, para serem considerados válidos, são ensinados aos demais membros como a maneira correta para se perceber, se pensar e sentir-se em relação àqueles problemas. 
Schein $(1992 ; 2001)$ analisa ainda a cultura organizacional a partir de diferentes níveis. Estes níveis referem-se ao grau em que o fenômeno cultural é visível ao observador. Portanto, o autor delimita três, que são os artefatos, os valores e os pressupostos básicos.

O primeiro nível, os artefatos, são as manifestações, as estruturas e os processos visíveis da cultura, como as festas, os ritos e as confraternizações que a organização promove. É o nível mais fácil de perceber, sendo tudo o que se vê, ouve e sente na empresa, ou seja, todas as formas de expressão que a organização apresenta de forma visível para todas as pessoas. Outros exemplos desse nível é a arquitetura, a tecnologia, a linguagem, os mitos e as histórias contadas pela organização.

Já os valores e ideologias são as regras, princípios, normas, valores e ética que orientam os fins e os meios de uma sociedade. Este nível está vinculado aos objetivos, às metas e estratégias que a organização prega. Ele é uma forma de moldar o comportamento dos indivíduos e grupos da organização, através das crenças e valores, pois estes servem como guia para os membros agirem em situações incontroláveis ou difíceis. Nesse nível é que a filosofia e a ideologia da organização começam a ser personificada.

Os pressupostos básicos e as premissas, por sua vez, são os valores subjacentes e inconscientes sobre a natureza da verdade e da realidade humana. São advindos de um processo longo de aprendizagem, no qual os indivíduos sofrem nos momentos relacionados às soluções adequadas utilizadas em cada problema organizacional. Ele está mais relacionado com as atitudes intrínsecas da organização, as verdades implícitas que os membros da organização pensam, sentem, percebem e compartilham em decorrência da experiência conjunta. Dessa forma, é possível ver a cultura em três níveis distintos e de forma diferenciada, pois a cultura pode ser tanto algo visível aos demais, como algo que está subentendido no comportamento dos indivíduos dentro de cada organização.

A complexidade inerente à cultura organizacional, além da sua ambigüidade como característica fundamental passa a ficar evidente no momento em que diversos níveis são atrelados a sua definição. Alcadipani e Crubellate (2003, p.66) reforçam essas características, abordando a cultura como "uma teia de indivíduos conectados fraca e esporadicamente, ligados por suas posições cambiantes em uma variedade de assuntos e circunstâncias". Eles complementam ainda que as manifestações e as fronteiras presentes nas subculturas das organizações são vistas como, multifacetadas, altamente flutuantes e permeáveis, além de seus significados serem, necessariamente, abertos a várias interpretações diferentes.

Portanto, essa ambigüidade e complexidade da cultura podem gerar várias definições. Para Dias (2008), existem duas formas de delinear a cultura organizacional. Inicialmente, ele apresenta a cultura como sendo um conjunto de valores e crenças que os membros da organização possuem em comum, de forma a definir o sentimento e a reação que orienta na tomada de decisão. A outra definição é apresentada como a interação das estruturas, dos processos de decisões e dos sistemas de controle da organização com os valores e crenças compartilhados pela organização. 0 autor reforça ainda que a cultura organizacional oferece coesão e sentido à como os indivíduos irão agir nas organizações. Assim, ele ressalta a implicação que a cultura pode ter no contexto organizacional e nas atitudes dos membros da empresa.

Corroborando com essa implicação nos indivíduos, Hofstede (1998) ressalta a cultura como uma característica não individual da organização, na qual é mensurada e manifestada no comportamento verbal e não verbal dos membros organizacionais de forma a agregar para o 
seu nível de unidade organizacional. As definições do que se deseja ou não em uma organização terá implicações diretas nos colaboradores, fazendo com que eles orientem suas ações de acordo com o contexto que a organização estabelece. Fernandes e Zanelli (2006) afirmam que os vários elementos organizacionais, ao serem apresentados aos colaboradores, fornecem um direcionamento para todas as pessoas que fazem parte do contexto organizacional, de forma a todas elas buscarem uma identidade com os padrões seguidos pela empresa.

\section{IMPORTÂNCIA DA CULTURA ORGANIZACIONAL}

Corroborando com as definições abordadas anteriormente, Schein (2001) afirma que a importância da cultura organizacional está presente nas tomadas de decisões da organização, pois, de acordo com ele, a força cultural existente pode ter conseqüências imprevistas e indesejáveis. Isto ocorre pelo fato da cultura organizacional está presente nas estratégias, nos objetivos e no modo de operação da empresa. Portanto, para que as decisões sejam tomadas, é preciso que os gerentes tenham consciência de como a cultura está disseminada pelos seus membros.

Segundo Santos (2000), a cultura é um dos principais elementos organizacionais que pode condicionar tanto como um empecilho para o aumento da produtividade, como pode ser um grande impulsionador para um alto nível de desempenho organizacional. Ela constatou, com sua pesquisa, que existiu uma correlação positiva entre desempenho e cultura. Assim, a autora pôde constatar que na mesma proporção que ocorreu o aumento na força cultural também aumentou o desempenho organizacional.

Asseverando a existência e importância dessa força cultural, Shiva e Roy $(2008$, p. 68) afirmam que "em uma cultura organizacional forte, os empregados entendem o que é esperado por eles". Eles abordam essa cultura forte como o sentimento dos funcionários de que os valores e os objetivos estão bem aderidos entre os membros da organização. Assim, se a cultura está bem disseminada entre os funcionários de forma que eles tenham convicção do que a organização espera deles, então os membros irão agir em prol do objetivo principal da organização.

Além dessa influência que a força cultural tem no comportamento dos membros da organização, existem diversas outras funções que a cultura pode exercer em uma empresa. Dias (2003) aborda algumas dessas funções inerentes à cultura: estabelece os limites, ao definir os papéis de cada integrante e criar distinções entre as organizações; transmite um senso de identidade, de pertencer entre os membros; facilita o compromisso dos indivíduos, com algo acima dos interesses individuais; fortalece a estabilidade do sistema organizacional; oferece sentido ao modo de como fazer as coisas, guiando e moldando as atitudes e comportamentos dos indivíduos. Assim, as funções da cultura de uma organização terão o objetivo de conter os dois principais problemas abordados por Schein (1992) a integração interna dos membros e a adaptação da organização ao meio em que está inserida.

\section{PRÁTICAS E VALORES ORGANIZACIONAIS}

Uma forma de abordar a cultura organizacional é através das suas práticas e valores organizacionais. Hofstede et al (1990), através de sua pesquisa, classificaram quatro categorias de manifestações da cultura: os valores, os rituais, os símbolos e os heróis. De acordo com eles, os símbolos, os rituais e os heróis fazem parte das práticas organizacionais, pois são características visíveis ao observador e que podem ser modificadas, à medida que 
suas mudanças sejam planejadas. Isto é, os rituais são caracterizados pelos autores como sendo atividades coletivas, indispensáveis socialmente. Já os símbolos são apresentados como palavras, figuras, objetos ou gestos que tenham um significado único para a cultura. Os heróis, por sua vez, representam pessoas, reais ou imaginárias, mortas ou vivas, com prestígios diante da cultura organizacional que pode servir como modelo de comportamento entre os membros.

Mallak (2001) ressalta as práticas organizacionais como o componente mais complexo da cultura organizacional, pois elas podem tanto ser a razão instrumental da organização, como podem levar uma mensagem importante da cultura aos seus membros. Assim, as práticas têm como principal objetivo transmitir mensagens aos valores culturais básicos da organização que são reforçados em todo momento que as práticas são executadas. Contrapondo-se a elas, segundo Hofstede et al (1990), está o centro da cultura, formado pelos valores. Estes se referem aos sentimentos, não especificamente racional ou irracional, bom ou ruim, que são raramente discutíveis e normalmente inconscientes. Os valores, apesar de não poderem ser observados, são manifestados no comportamento de cada indivíduo.

As práticas organizacionais referem-se à parte visível da cultura, assim, elas são responsáveis em planejar a mudança. Já os valores representam a parte invisível da cultura. Os valores fazem mudança, porém não conforme os planos de qualquer pessoa, mas de acordo com sua própria lógica (HOFSTEDE, 1998). Baseados nessas referências de valores e práticas organizacionais, Ferreira et al (2002) apresentaram um instrumento, que foi utilizado nesta pesquisa, para avaliar a cultura organizacional por meio de seus valores e suas práticas, denominado de Instrumento Brasileiro para Avaliação da Cultura Brasileira - IBACO. Neste modelo é possível observar os valores e as práticas priorizadas nas organizações.

Segundo Hofstede (1991) as práticas e os valores também podem ser utilizados para diferenciar a cultura organizacional da cultura nacional. Isto é, o autor aborda que o termo "cultura" não pode ser utilizado por ambas, como se fosse um fenômeno idêntico. Ele ressalta que elementos da cultura nacional afetam algumas atitudes da cultura organizacional e que a diferença entre elas está relacionada aos papéis de cada uma como forma de manifestação da cultura.

Abordando as práticas em uma cultura nacional, esta pode ser representada através dos seus símbolos, heróis e rituais, ou seja, manifestações superficiais da cultura que, para os indivíduos, são o que determinam o significado de suas práticas e trata-se de indicadores ultrapassados. Destrinchando cada uma delas, os símbolos nacionais podem ser observados através do uso das mesmas palavras da moda, dos mesmos estilos de roupa utilizados e a compra dos mesmos produtos. Já os heróis seriam as pessoas assistirem aos mesmos shows televisivos e filmes. E os rituais da cultura nacional são visualizados nas mesmas atividades de lazer e na realização dos mesmos tipos de esportes. Porém no que se referem aos valores nacionais, cada país apresenta uma expressiva diferença entre eles (HOFSTEDE, 1991).

A existência do fato no qual a diferença entre os valores da cultura nacional é maior do que as práticas é explanada por Hofstede (1991) através dos lugares que as pessoas aprendem os valores, ou seja, onde ocorre a socialização dos indivíduos com os demais. Os valores normalmente são adquiridos nos primeiros anos de vida, principalmente na vizinhança, no ambiente familiar e, posteriormente, na vida escolar. Assim, a maioria dos valores básicos individuais é formada nos dez primeiros anos de vida do indivíduo.

Além dos valores, dos rituais, dos símbolos e dos heróis abordados pelas práticas e valores 
organizacionais, Freitas (1991) apresenta outros elementos pertencentes à cultura organizacional que são, freqüentemente, citados na literatura. As estórias e os mitos, de acordo com a autora, são exemplos desses elementos. A estória retrata eventos narrados pelos membros que ocorreram na organização, já os mitos não apresentam sustentação nos fatos, referem-se às estórias consistentes com os valores da organização.

Os tabus, as normas e o processo de comunicação também são elementos da cultura apresentados por Freitas (1991). Os tabus enfatizam o que não é permitido na organização, orientam o comportamento dos membros a demarcar as áreas proibidas da empresa. As normas, por sua vez, podem ser escritas ou não, elas defendem o que se espera dos membros organizacionais e o que é aceito e sancionado pelo grupo. 0 processo de comunicação pode se tornar importante quando há a transformação do corriqueiro, da rotina em algo brilhante, inovador. Esse processo refere-se às redes de relacionamento da organização e os papéis informais que comportam como, por exemplo, os padres, contadores de estórias, fofoqueiros e conspiradores.

\section{METODOLOGIA}

A pesquisa é caracterizada como de natureza descritiva, pois se pretende descrever as características de uma população, e também explicativa, pois tem a preocupação de identificar os fatores que contribuem para ocorrência dos fenômenos (GIL, 2007). A pesquisa apresentou uma análise quantitativa dos dados, por ter empregado a quantificação na coleta de informações e no tratamento dos dados.

A população pesquisada inclui os colaboradores de três hospitais da rede privada de Natal/RN. A amostra utilizada foi a não-probabilística por acessibilidade ou por conveniência. Nos hospitais obteve-se um total de 920 colaboradores e, através da fórmula de Cocrhan (1977) obteve-se um total de 279 indivíduos. Assim, a parcela de indivíduos a serem pesquisados foi calculada de forma proporcional a cada hospital, ou seja, ao Hospital A foi preciso uma amostra de 116 colaboradores, no Hospital B, 28 e, no Hospital C, 135 colaboradores. A amostra final totalizou 283 sujeitos, um número superior ao obtido na fórmula (279).

0 instrumento de cultura organizacional que foi utilizado é o Instrumento Brasileiro para Avaliação da Cultura Organizacional - IBACO desenvolvido por Ferreira et.al. (2002). Este instrumento apresenta 30 itens distribuídos igualitariamente nos seis fatores abordados. Dentre os fatores têm-se três relacionados aos valores que são o profissionalismo cooperativo, o profissionalismo competitivo e a satisfação e bem-estar dos empregados; e três fatores referentes às práticas que são a integração externa, a recompensa e o treinamento e a promoção do relacionamento interpessoal. 0 instrumento apresenta uma escala na qual intenciona medir a atitude do indivíduo, denominada escala de likert. Assim, o IBACO apresenta a escala com cinco pontos de variação, indo de "não se aplica de modo nenhum" (1) até "aplica-se totalmente" (5).

A coleta de dados foi realizada de 28 de agosto a 10 de setembro de 2008, sendo a aplicação do questionário iniciada de forma direta entre os colaboradores, realizando-se de maneira individual ou coletiva, dependendo da situação na qual o colaborador era abordado. Para a análise quantitativa dos dados foram utilizadas as técnicas estatísticas de tendência central através de aplicativos computacionais, como o software estatístico SPSS. Dentre as técnicas usadas, utilizou-se inicialmente a técnica de análise fatorial nas variáveis abordadas pelo IBACO sobre cultura organizacional, separando-se as 15 variáveis das práticas das 15 
variáveis dos valores organizacionais. Para a utilização desta técnica para análise dos dados, Hair et al (2005) afirma que é preciso um mínimo de cinco vezes o valor das variáveis. Desse modo, a quantidade conseguida na pesquisa está condizente com o tamanho considerado adequado para a realização desta técnica.

\section{ANÁLISE DOS DADOS}

No que se referem às práticas organizacionais, as 15 variáveis relacionadas ao tema foram submetidas à análise fatorial. Para a análise de confiabilidade da amostra, foi utilizado o teste de alfa de Cronbach, priorizando-se valores acima ou igual a 0,70. Outro teste para examinar a adequação da análise fatorial utilizado foi o teste de Bartlett de esfericidade, no qual "fornece a probabilidade estatística de que a matriz de correlação tenha correlações significantes entre pelo menos algumas das variáveis" (HAIR et al, 2005 p.98).

Posteriormente, foi necessário analisar a matriz fatorial quanto à comunalidade de cada uma das variáveis do modelo. Estas comunalidades representam a quantia de variância explicada pela solução fatorial para cada variável. Portanto, elas precisam estar acima de 0,50 em cada variável, para que a variável possa atender a níveis de explicação aceitáveis (HAIR et al, 2005).

Após uma análise preliminar dos testes e da matriz anti-imagem, observou-se uma boa adequação na amostra. Ao serem analisadas as comunalidades das práticas, no entanto, algumas variáveis apresentaram índices abaixo do recomendável. As duas variáveis com baixos índices foram: Os empregados têm ampla liberdade de acesso aos diretores; e, As inovações são em geral introduzidas para atender às necessidades do mercado. Assim, essas duas questões foram retiradas da análise fatorial.

A análise fatorial foi então realizada nas 13 variáveis restantes. 0 teste de Bartlett apresentou uma significância de 0,0001, na qual demonstra um nível de correlação não-nula adequada para a amostra utilizada. Quanto ao KMO, a amostra apresentou um índice de 0,894, asseverando o nível admirável que a amostra apresenta. A partir desses dois testes, então, é possível ter consistência quanto a prosseguir na utilização da análise fatorial (HAIR et al, 2005).

A análise fatorial apresentou três fatores que explicam $64 \%$ da variância total. A rotação ortogonal varimax foi utilizada e os índices de carga fatorial foram considerados apenas os acima de 0,50. As cargas fatoriais de cada variável estão especificadas na Tabela 4. 
Tabela 1: Cargas fatoriais de cada variável das práticas organizacionais

\begin{tabular}{l|c|c|c}
\hline \multicolumn{1}{c|}{ Variáveis } & \multicolumn{2}{c}{ Fatores } \\
\cline { 2 - 4 } & 1 & 2 & 3 \\
\hline $\begin{array}{l}\text { Os empregados são premiados quando apresentam um desempenho que se destaca } \\
\text { dos demais }\end{array}$ & 0,843 & & \\
\hline Os empregados costumam ser premiados quando alcançam metas pré-estabelecidas & 0,819 & & \\
\hline Os empregados que apresentam idéias inovadoras costumam ser premiados & 0,781 & & \\
\hline $\begin{array}{l}\text { Eventos sociais com distribuição de brindes são comumente realizados para os } \\
\text { empregados }\end{array}$ & 0,688 & & \\
\hline É prática comum a comemoração dos aniversários pelos empregados & 0,650 & & \\
\hline As inovações costumam ser introduzidas através de programas de qualidade & 0,583 & & \\
\hline $\begin{array}{l}\text { O acompanhamento e atendimento das necessidades dos pacientes é feito } \\
\text { constantemente }\end{array}$ & & 0,787 & \\
\hline Persegue-se a excelência dos serviços como forma de satisfazer aos pacientes & & 0,774 & \\
\hline O atendimento às necessidades do paciente é uma das metas mais importantes & & 0,764 & \\
\hline Os chefes imediatos são como pais para os empregados & & & 0,814 \\
\hline Mantêm-se relações amigáveis com os pacientes & & & 0,664 \\
\hline Os empregados se relacionam como se fossem uma grande família & & & 0,602 \\
\hline As relações entre empregados e membros do alto escalão são cordiais e amigáveis & & & 0,575 \\
\hline
\end{tabular}

Fonte: Dados da pesquisa, 2008

Dos $64 \%$ de variabilidade obtida para os três fatores destacados pela análise, o fator 1 explica 28,8\%; o fator 2 explica 19,28\%; e o fator 3 explica 15,92\%. Através das especificações de cada variável nos fatores, foi possível nomeá-los. Os três fatores relacionados às práticas organizacionais dos hospitais apresentados na análise fatorial foram nomeados com base nas práticas abordadas por Ferreira et al (2002). Aconteceram algumas divergências quanto às variáveis que faziam parte de uma prática, de acordo com o modelo original, mas que nessa análise se agrupou a outra prática. No Quadro 1 estão agrupados os três fatores com suas respectivas variáveis.

Quadro 1: Fatores e variáveis das práticas organizacionais

\begin{tabular}{|c|c|}
\hline Fatores & Variáveis \\
\hline \multirow{6}{*}{$\begin{array}{lr}1-\text { Prática } & \text { de } \\
\text { recompensa } & \mathrm{e} \\
\text { treinamento } & \end{array}$} & Os empregados que apresentam idéias inovadoras costumam ser premiados. \\
\hline & $\begin{array}{l}\text { Os empregados são premiados quando apresentam um desempenho que se destaca dos } \\
\text { demais. }\end{array}$ \\
\hline & É prática comum a comemoração dos aniversários pelos empregados. \\
\hline & $\begin{array}{l}\text { Eventos sociais com distribuição de brindes são comumente realizados para os } \\
\text { empregados. }\end{array}$ \\
\hline & As inovações costumam ser introduzidas através de programas de qualidade. \\
\hline & Os empregados costumam ser premiados quando alcançam metas pré-estabelecidas. \\
\hline \multirow{3}{*}{$\begin{array}{l}2-\text { Prática de } \\
\text { integração externa }\end{array}$} & $\mathrm{O}$ atendimento às necessidades do paciente é uma das metas mais importantes. \\
\hline & Persegue-se a excelência dos serviços como forma de satisfazer aos pacientes. \\
\hline & $\begin{array}{l}\text { O acompanhamento e atendimento das necessidades dos pacientes são feitos } \\
\text { constantemente. }\end{array}$ \\
\hline \multirow{4}{*}{$\begin{array}{ll}3-\text { Prática } & \text { da } \\
\text { promoção } & \text { do } \\
\text { relacionamento } & \\
\text { interpessoal } & \end{array}$} & Mantêm-se relações amigáveis com os pacientes. \\
\hline & Os chefes imediatos são como pais para os empregados. \\
\hline & As relações entre empregados e membros do alto escalão são cordiais e amigáveis. \\
\hline & for \\
\hline
\end{tabular}

Fonte: Dados da pesquisa, 2008 
0 fator 1 apresentou práticas relacionadas aos colaboradores quanto ao sistema de recompensa e treinamento adotados pela empresa e uma variável relacionada com o relacionamento interpessoal que foi a comemoração dos aniversariantes. Este fator foi, então, identificado como a Prática de recompensa e treinamento abordada pelo IBACO. Asseverando um alto índice de confiabilidade, esta prática apresentou um alfa de Cronbach de 0,878.

A variável É prática comum a comemoração dos aniversários pelos empregados pode ter sido agrupada a esse fator, por a comemoração dos aniversariantes não ser uma prática tão constante nos hospitais da região, de acordo com entrevistas informais realizadas. Além de ser realizada de maneira mais setorial, ou seja, restringindo a alguns colaboradores do setor.

Assim, esta prática foi interpretada como uma recompensa para os colaboradores, de forma diferente à interpretação feita no modelo IBACO. 0 fator 2 associou variáveis relacionadas ao atendimento do paciente, ao planejamento estratégico e a tomada de decisão relacionada ao cliente externo. Portanto, ele foi nomeado de Prática de integração externa, apresentando as três variáveis abordadas pelo instrumento original nesta prática. 0 índice de confiabilidade apresentado por esta prática foi de 0,780; atingindo, assim, o nível desejável.

0 terceiro fator abordou as variáveis referentes à promoção das relações interpessoais e satisfação do empregado, além de ter apresentado uma prática voltada para o relacionamento interpessoal com os pacientes. Este fator foi identificado, de acordo com o IBACO, como a Prática da promoção do relacionamento interpessoal. Ele apresentou um índice de confiabilidade, alfa de Cronbach menor do que as outras duas práticas, no entanto manteve-se no nível aceitável com 0,712 .

A variável Mantêm-se relações amigáveis com os pacientes, agrupada nesse último fator, é originalmente do segundo fator, o de integração externa. No entanto, essa variável agrupou-se nesse outro fator, talvez por haver uma maior distinção entre os dois fatores. Isto é, no primeiro fator está a prática mais relacionada ao atendimento propriamente dito dos pacientes. Já no fator do relacionamento interpessoal está a relação amigável existente entre pacientes e colaboradores.

Estas práticas, apesar de Mallak (2001) apresentar como os componentes mais complexos da organização, elas podem ser comparadas ao primeiro nível abordado por Schein (1992; 2001). Neste nível estão as manifestações visíveis da organização, como as confraternizações apresentadas na Prática de recompensa e treinamento. Essa prática também pode ser comparada com as manifestações apresentadas por Hofstede et al (1990), ou seja, os rituais organizacionais como a comemoração dos aniversariantes e a realização de eventos sociais, estão presentes nesta prática.

As demais manifestações apresentadas por Hofstede et al (1990) sobre as práticas, através dos símbolos e dos heróis podem ser observadas nas outras duas práticas analisadas. A Prática de integração externa, por exemplo, pode ser analisada de acordo com os símbolos utilizados para a melhora do atendimento ao paciente, ou seja, as palavras e os gestos que representam uma melhor qualidade com o atendimento. Quanto a Prática do relacionamento interpessoal, de acordo com algumas entrevistas informais realizadas durante a aplicação do questionário, pode ser comparada aos heróis abordados por Hofstede et al (1990), no qual se têm os chefes imediatos e o pessoal do alto escalão como modelos a serem seguidos pelos demais colaboradores.

Outra ideologia relacionada às práticas, é que elas podem representar o que Kotter e Heskett 
(1994) abordam como o nível mais fácil de acontecer mudanças, por estarem mais visíveis aos indivíduos. Isto é, estes autores afirmam que se trata dos padrões de comportamento que os membros da organização incentivam os demais colegas a seguir. Portanto, a Prática do relacionamento interpessoal insere neste contexto ao ter vinculados a ela as relações existentes entre os membros organizacionais.

Os mesmos procedimentos estatísticos abordados nas práticas organizacionais foram repetidos no que se refere aos valores organizacionais. Assim, as 15 variáveis pertencentes aos valores foram analisadas através da análise fatorial.

Quanto as comunalidades, as variáveis relacionadas aos valores organizacionais apresentaram índices baixos em quatro variáveis. Três das quatro variáveis pertenciam segundo Ferreira ET al (2002), ao Valor de profissionalismo competitivo que são: Somente os bons empregados recebem benefícios que lhes garantem um melhor bem-estar; A criatividade é um dos requisitos básicos para a ocupação de cargos gerenciais; e, $O$ crescimento profissional é considerado indispensável à permanência do empregado na casa. A outra variável relacionada ao baixo índice de comunalidade que foi retirada da análise foi: Os empregados que demonstram dedicação e espírito de colaboração são os melhores modelos a serem seguidos; relacionado ao Valor de profissionalismo cooperativo.

Portanto, ao serem retiradas as quatro variáveis com baixo poder de explicação, a análise fatorial foi realizada, então, nas 11 variáveis restantes, referentes aos valores. Os testes finais apresentados, também apresentaram índices adequados da amostra. 0 KMO apresentou um índice de 0,916, valor maior do que o obtido pelas práticas, garantindo o nível de adequação da amostra. 0 teste de Bartlett também obteve um nível de significância adequada para a amostra, com 0,0001 .

A análise fatorial apresentou dois fatores representando 68,37\% da variância total explicada, utilizando-se novamente a rotação varimax e índices de cargas fatoriais acima de 0,50. Na tabela a seguir estão distribuídas as variáveis em cada fator com suas cargas fatoriais.

Tabela 2: Cargas fatoriais de cada variável dos valores organizacionais

\begin{tabular}{l|c|c}
\hline \multicolumn{1}{c|}{ Variáveis } & \multicolumn{2}{c}{ Fatores } \\
\cline { 2 - 3 } & 1 & 2 \\
\hline $\begin{array}{l}\text { Programas destinados a melhorar o bem-estar dos empregados são implementados e } \\
\text { testados }\end{array}$ & 0,857 & \\
\hline O profissionalismo dos empregados é visto como uma grande virtude & 0,852 & \\
\hline Investe-se no crescimento profissional dos empregados & 0,819 & \\
\hline Programas para aumentar a satisfação dos empregados são regularmente desenvolvidos & 0,816 & \\
\hline A preocupação do empregado com a qualidade de seu serviço é bem vista & 0,800 & \\
\hline O esforço e a dedicação ao trabalho são qualidades bastante apreciadas & 0,793 & \\
\hline A preocupação em superar as dificuldades do dia-a-dia é vista como de grande valor & 0,793 & \\
\hline Os empregados recebem treinamento para poderem desenvolver sua criatividade & 0,790 & \\
\hline $\begin{array}{l}\text { As necessidades pessoais e o bem-estar dos funcionários constituem uma preocupação } \\
\text { constante da empresa }\end{array}$ & 0,757 & \\
\hline $\begin{array}{l}\text { A competição é valorizada, mesmo que de forma não sadia, porque o objetivo maior do } \\
\text { hospital é a produtividade e o lucro }\end{array}$ & & 0,860 \\
\hline A competição é vista como indispensável à obtenção de bons resultados & & 0,858 \\
\hline
\end{tabular}

Fonte: Dados da pesquisa, 2008 
Os fatores que representam os valores organizacionais apresentaram discordâncias quanto aos abordados pelo modelo original. Só o primeiro fator dos valores, dos $68,37 \%$ de variabilidade total, apresentou um percentual de 54,1\%. Isso ocorre pelo fato de que este primeiro fator apresentar variáveis de dois fatores distintos, conforme abordado por Ferreira et al (2002). 0 Quadro 2 a seguir aborda as variáveis pertencentes a cada fator.

Quadro 2: Fatores e variáveis dos valores organizacionais

\begin{tabular}{|c|c|}
\hline Fatores & Variáveis \\
\hline \multirow{9}{*}{$\begin{array}{l}\text { 1 - Valor de satisfação, } \\
\text { bem-estar e cooperação } \\
\text { do empregado }\end{array}$} & $\begin{array}{l}\text { As necessidades pessoais e o bem-estar dos funcionários constituem uma } \\
\text { preocupação constante da empresa. }\end{array}$ \\
\hline & Investe-se no crescimento profissional dos empregados. \\
\hline & Os empregados recebem treinamento para poderem desenvolver sua criatividade. \\
\hline & $\begin{array}{l}\text { Programas para aumentar a satisfação dos empregados são regularmente } \\
\text { desenvolvidos. }\end{array}$ \\
\hline & A preocupação do empregado com a qualidade de seu serviço é bem vista. \\
\hline & O esforço e a dedicação ao trabalho são qualidades bastante apreciadas. \\
\hline & $\begin{array}{l}\text { Programas destinados a melhorar o bem-estar dos empregados são implementados } \\
\text { e testados. }\end{array}$ \\
\hline & O profissionalismo dos empregados é visto como uma grande virtude. \\
\hline & $\begin{array}{l}\text { A preocupação em superar as dificuldades do dia-a-dia é vista como de grande } \\
\text { valor. }\end{array}$ \\
\hline \multirow{2}{*}{$\begin{array}{l}2-\text { Valor } \\
\text { profissionalismo } \\
\text { competitivo }\end{array}$} & $\begin{array}{l}\text { A competição é valorizada, mesmo que de forma não sadia, porque o objetivo } \\
\text { maior do hospital é a produtividade e o lucro. }\end{array}$ \\
\hline & A competição é vista como indispensável à obtenção de bons resultados. \\
\hline
\end{tabular}

Fonte: Dados da pesquisa, 2008

No primeiro fator as nove variáveis relacionadas, pertenciam originalmente a dois valores distintos que são o valor de satisfação e bem-estar dos empregados e o valor de profissionalismo cooperativo. Esses dois fatores originais se uniram por apresentarem comportamentos estatisticamente idênticos, assim, esses dois valores foram condensados em um só, apresentando as cinco variáveis do valor de satisfação e bem-estar e as outras quatro variáveis do profissionalismo cooperativo, formando, então, o valor de satisfação, bem-estar e cooperação dos empregados. Uma possível explicação dessa união é que a cooperação existente nas empresas gera uma satisfação e um bem-estar nos empregados.

Este primeiro fator está relacionado à valorização dos colaboradores que demonstram espírito de colaboração, dedicação, iniciativa. Ele está vinculado a valores que contribuem para o alcance dos objetivos comuns da organização, bem como, para a humanização do local de trabalho, de modo a torná-lo agradável e prazeroso. Portanto, este fator engloba tanto a valorização do empregado quanto a sua habilidade e profissionalismo, quanto à motivação, satisfação e bem-estar no ambiente de trabalho. Ele apresentou um ótimo índice de confiabilidade interna com um valor de 0,933 .

Este primeiro valor organizacional pode também ser visto como pertencente aos dois últimos níveis abordados por Schein (1992; 2001), na qual estão os valores mais visíveis e os mais subjacentes. Em relação ao segundo nível apresentado por este autor, os dos valores e das ideologias organizacionais estão as normas, os objetivos e as regras da organização. Desta forma, as variáveis que formavam apenas o Valor de satisfação e bem-estar dos empregados, apresentam elementos relacionados ao investimento e ao treinamento dos funcionários, podendo ser vinculado aos objetivos organizacionais. 
Em relação às variáveis que formavam inicialmente, somente o Valor de profissionalismo cooperativo apresenta componentes inerentes ao outro nível apresentado por Schein (1992; 2001). 0 nível da premissa e dos pressupostos básicos, explorado pelo referido autor, referese às verdades compartilhadas pelos indivíduos, as atitudes em relação à cooperação entre eles. Isto é, neste valor os colaboradores percebem, pensam e sentem conforme o esforço, a dedicação e o profissionalismo são explorados pela organização. A união desses dois tipos de valores ressalta o nível apresentado por Kotter e Heskett (1994), no qual aborda como o nível mais profundo e menos visível da cultura organizacional e que se refere aos valores compartilhados pelos membros da organização.

0 segundo fator apresentou um percentual de explicação quanto à variabilidade dos dados de $14,27 \%$. Ele foi caracterizado com duas variáveis relacionadas ao valor de competição entre os empregados. Neste fator, observa-se a valorização do desempenho individual na execução das tarefas, independentemente se para alcançar o objetivo almejado, precise "passar por cima" dos colegas. De acordo com Ferreira et al (2002) este fator está relacionado ao Valor de profissionalismo competitivo.

Este segundo fator apresentou um coeficiente de alfa de Cronbach um pouco abaixo do valor aceitável, com 0,680. No entanto, Hair et al (2005) aborda que a avaliação feita com esse índice é a relação positiva com o número de itens na escala. Como esse fator só apresentou duas variáveis, então, esse número de itens interferiu no índice. Além disso, outra explicação pode ser considerada em relação a esse baixo coeficiente de confiabilidade. De acordo com Santos (2000), os valores servem como critério de avaliação das ações dos outros indivíduos e Dubrin (2003) também ressaltam os valores como algo que é importante para a pessoa e serve como orientação para agir. Assim, ressaltar, principalmente a valorização da competição dentro da organização, é avaliar as ações das pessoas de forma competitiva e afirmar que elas julgam isso importante.

\section{CONCLUSÃO}

A utilização do Instrumento Brasileiro para Avaliação da Cultura Organizacional - IBACO foi útil para observar a utilização das práticas e dos valores no ambiente organizacional, de acordo com a percepção dos colaboradores. A distribuição das variáveis para cada prática e valor apresentado pelo modelo IBACO, divergiu do encontrado na presente pesquisa. No entanto, foi possível observar como as práticas e os valores podem ser visualizados nos hospitais pesquisados.

Quanto às práticas detectada, a que mais se destacou, por ter o índice de confiabilidade maior foi a de recompensa e treinamento, demonstrando que os profissionais detectam esse tipo de prática na empresa. Outra prática ressaltada foi a de integração externa, na qual evidencia a preocupação que os hospitais apresentam com o atendimento aos pacientes. A Prática da promoção do relacionamento interpessoal foi menos enfatizada ao ser comparada com as outras duas. Provavelmente, isso possa ter ocorrido pelo fato de alguns profissionais da rede hospitalar passar apenas o horário de plantão pré-determinado, restringindo, assim, um maior relacionamento entre os colaboradores.

No que concerne aos valores, foi constatado que o Valor de satisfação, bem-estar e cooperação do empregado obteve um grande destaque, tanto pelo valor do índice de confiabilidade ter sido alto, quanto pela quantidade de fatores com altas cargas fatoriais. Isso enfatiza a valorização que os hospitais oferecem aos seus colaboradores. Já ao Valor de profissionalismo 
competitivo, não foi muito enfatizado, corroborando que os hospitais pesquisados não valorizam a competição entre seus profissionais.

\section{REFERÊNCIAS}

ALCADIPANI, Rafael; CRUBELLATE, João Marcelo. Cultura organizacional: generalizações improváveis e conceituações imprecisas. Revista de Administração de Empresas. v.43, n.2, p. 64-77, abr/maio/jun. 2003.

COCHRAN, William G. Sampling tecniques. New York: J. Wiley, 1977.

DIAS, Reinaldo. Cultura organizacional. São Paulo: Alínea, 2003.

Sociologia das organizações. São Paulo: Atlas, 2008.

DUBRIN, Andrew J. Fundamentos do comportamento organizacional. São Paulo: Pioneira Thomson Learning, 2003.

FERNANDES, Karina Ribeiro; ZANELLI, José Carlos. 0 processo de construção e reconstrução das identidades dos indivíduos nas organizações. Revista de Administração Contemporânea. V.10, n.1, p.1-12, jan/mar. 2006.

FERREIRA, Maria Cristina et al. Desenvolvimento de um instrumento brasileiro para avaliação da cultura organizacional. Estudos de Psicologia. v.7, n.2, p.271-280, jul/dez. 2002.

GIL, Antônio Carlos. Métodos e técnicas de pesquisa social. 5. ed. São Paulo: Atlas, 2007.

HAIR JR, Joseph F. et al. Análise multivariada de dados. 5. ed. Porto Alegre: Bookman, 2005.

HOFSTEDE, Geert. Attitudes, values and organizational culture: disentangling the concepts. Organization Studies. v.19, n.3, p. 477-492, maio 1998.

. et al. Measuring organizational cultures: a qualitative and quantitative study across twenty cases. Administrative Science Quartely. v. 35, n.2, p. 286-316, jun. 1990.

KOTTER, John P; HESKETT, James L. A cultura corporativa e o desempenho empresarial. São Paulo: Makron Books, 1994.

MALLAK, Larry. Understanding and changing your organization's culture. Industrial Management. v. 43, n. 2, p. 18-24, mar/abr. 2001

SANTOS, Neusa Maria Bastos F. Cultura organizacional e desempenho: pesquisa, teoria e aplicação. Lorena: Stiliano, 2000.

SCHEIN, Edgar H. Organizational culture and leadership. 2.ed. São Francisco: Jossey-Bass Publishers, 1992.

. Guia de sobrevivência da cultura corporativa. Trad.: Monica Braga. Rio de Janeiro: José Olympio, 2001.

SHIVA, Mahalinga M.S.A.; ROY, Santanu. A conceptual modelo of transformational leadership, organizacional culture and organizacional effectiveness for NGOs in the Indian context. The Icfaian Journal of Management Research. v.8, n. 4, p. 63-73, 2008. 